\title{
Philosophical Challenges in Teaching Evolution
}

\author{
Richard A. Richards
}

Published online: 23 January 2008

(C) Springer Science + Business Media, LLC 2008

Keywords Teaching - Evolution · Philosophical challenges · Biblical literalism

\section{Introduction: Objections to Evolution}

In the infamous Scopes "Monkey trial" of 1925, John Scopes, a substitute high school biology teacher in Tennessee, was prosecuted for violating legislation against the teaching of Darwinian evolution. Since this trial and the film "Inherit the Wind," that dramatized it, the American South has been stereotyped as antievolutionist, based on a Biblical literalist fundamentalism. While there is certainly some truth to this stereotype, the reality then and now is more complicated. The prosecuting lawyer for the state of Tennessee, for instance, was a former three-time Democratic presidential candidate from Illinois, William Jennings Bryan, who may have argued against evolution on the basis of its conflict with the Bible but also opposed it on the basis of his worries about its apparent implications for human equality (Smith 1966, pp. 59-60). This worry about the political implications of evolution has also been apparent more recently. After the initial publication of his Sociobiology in 1975, with its evolutionary approach to humans, E. O. Wilson was picketed and protested not by Biblical literalists but by activists of the political left, who objected not on the basis of traditional religious beliefs but on the basis of what they believed to be its undermining of progressive ideals against racism, sexism, and fascism in general (Segerstråle 2001).

R. A. Richards ( $\square)$

University of Alabama,

Tuscaloosa, AL, USA

e-mail: rrichard@bama.ua.edu
What all this suggests is that the worries many people have about evolution and the teaching of evolution are not always and only based on a commitment to creationism and Biblical literalism. Evolution challenges some of our most deeply entrenched philosophical commitments about human nature. It challenges a widespread belief that humans are somehow exempt from the laws of nature. This challenge in turn naturally raises questions about justification not raised by other less philosophically significant scientific theories. If we want to fully understand the opposition to evolution and the teaching of evolution, we need to understand these philosophical challenges posed by evolution.

My interest in addressing these philosophical challenges is motivated partly by my recent experience in the classroom that has seen fewer worries about evolution based on a creationist, Biblical literalism and more based on other issues. It is also motivated by the public positions of many scholars who seem to have reservations about evolution but not on the grounds of a creationist Biblical literalism. Few professional philosophers, for instance, are committed to a traditional religious stance, but many still have seemingly antievolutionary views, especially about humans. Similar attitudes are found in other disciples of the humanities and social sciences. We often take light notice of these other antievolutionary stances, focusing almost exclusively on opposition based on Biblical literalism. But by ignoring these other antievolutionary stances, we might be missing much of what is motivating the Biblical literalists as well.

In this essay, I will lay out what I believe to be the broader philosophical challenges facing the teaching of evolution. These challenges lie in the legitimate implications evolution has for human nature and activities and the subsequent demand for greater justification. I will begin with a brief description of the evolution-themed courses I teach and the 
ways that antievolutionary attitudes are manifested. I then sketch out a general worry that seems to be motivating at least some of these antievolutionary attitudes, a worry that originates in a variety of philosophical stances committed to a human "exemptionalism," which in turn has implications about proper explanations of human nature and activities. The problem is that a consistent evolutionary approach seems to undercut human exemptionalism in a variety of ways, and those committed to exemptionalism are loath to accept the evolutionary principles that undercut it. I will then explain the basic ways evolution seems to challenge exemptionalism. Finally, I will conclude with a few thoughts about how we might respond to these philosophical challenges.

Before continuing, however, two clarifications are in order. First, I will interpret the term 'evolution' broadly, to refer to the basic theories advanced by Darwin (origin of new species by modification, common ancestry, and change primarily by natural selection), as well as the many modern theoretical developments related to genetics, development, and more. Second, my own views are that this cluster of evolutionary theories is the only scientifically respectable understanding of the origin of species; and these theories are worth taking seriously because they are empiricaltestable by observation - and have been refined on the basis of observation. Third, the implications of evolution are farreaching and will ultimately change our intellectual landscape in profound ways. Philosophy in particular needs to pay close attention to what evolution reveals about how we think and what sorts of creatures we are.

\section{Teaching Evolution at the University of Alabama}

I teach courses on and about evolution in some form or other every semester at the University of Alabama, through the philosophy department and an interdisciplinary honorstype program. In the philosophy department, I regularly teach a course titled "Philosophy and Evolution," that begins historically with readings from pre-Darwinian theories of transmutation from Linnaeus (in the later editions of his Systema Naturae) to Lamarck; the influences on Darwin from Humboldt, Herschel, Lyell and Malthus; and Darwin's $(1964 ; 1981)$ own writing from his essays of 1842 and 1858 to his On the Origin of Species, and Descent of Man. Following this is often a section on the creationist challenge and intelligent design. Then, we may follow with some recent debates within evolutionary theory about macroevolution, levels of selection, etc. Following that are typical readings and discussions on human nature, race, sociobiology and evolutionary psychology, knowledge, ethics, and more.
Evolution also makes an appearance in a variety of other philosophy courses I teach as well. A course on "Theories of Human Nature," for instance, begins with traditional religious theories from the ancient Hebrew, Christian, and Asian traditions, then proceeds to the theories of the ancient Greek philosophers, and continues on into modern Marxist, Freudian, and ultimately Evolutionary theories. In a course on American Pragmatism, we look at how Darwin's evolutionary approach influenced the "classic" pragmatists Charles Pierce, William James, John Dewey, and Oliver Wendell Holmes, as well as contemporary pragmatists such as Thomas Kuhn.

In three courses I teach for the interdisciplinary, Blount Undergraduate Initiative, titled "Origins," "Possibilities," and "Worldviews," the coverage of evolution is less systematic and focused. We may read and discuss historical texts such as the 1858 essays of Wallace and Darwin, but emphasis is placed on more contemporary texts from E. O. Wilson (2000) and Stephen Jay Gould (2003), to the human population geneticist Luigi Luca Cavalli-Sforza, neuroscientist Gerald Edelman, and developmental linguist Steven Pinker. Non-evolutionary readings from literature and philosophy are also included, and one focus in these courses is the possibility of integrating evolutionary approaches into the intellectual background constituted by classic texts from Plato, Augustine, Shakespeare, Descartes, John Locke. John Stuart Mill, Karl Marx, Adam Smith, and more. We might ask, for instance, if and how the understanding of human nature derived from evolutionary biology can help us evaluate the political theories of Plato, Mill, Marx, and Smith. And we try to understand how evolutionary neuropsychology might illuminate the roles of reason and imagination we find represented in Shakespeare's Tempest or Descartes Meditations. Discussions in these classes often range far and wide, encompassing debates about religion, race and gender relations, civil and economic liberties, rights and obligations, individualism versus collectivism, and more.

The "Philosophy and Evolution" class rarely has any students committed to a creationism based on Biblical literalism. This is partly due to a self-selection, in that students who do not accept evolution are less likely to take a class organized around it. This is not to say, however, that there are no antievolutionary tendencies among the students. These tendencies rarely come out when discussing evolution in general, or of nonhuman species. Like the response to E. O. Wilson's Sociobiology in 1975, when discussion turns to Homo sapiens, the worries and objections start to appear. One worry appears when we discuss the application of "population thinking" to humans.

One of Darwin's conceptual innovations was the recognition of constant and inevitable variability within a species and across geographic ranges and the incorporation 
of this variability into his theorizing. Evolution not only implies that members of species vary, but that they must vary if there is to be natural selection and change. While Darwin had already been working on developing his evolutionary theories from 1837 on in his transmutation notebooks, it was not until he began his 8-year-long studies of barnacles in 1846 that he became convinced that variation was the rule rather than the exception. Few of my students worry about variation among barnacles, but many worry about variation among humans. If humans vary in general, there will be variation not just in physical traits but also in mental and behavioral traits. Worse, there may be variability across geographic ranges. Worse still, this variability is the basis for the natural selection and evolution of humans. Some humans are just better adapted to particular environments. Does this mean that humans are not all "equal"? And if so, does it imply that we can treat different people differently?

This worry typically gets raised in my interdisciplinary classes as well. In these classes, we explicitly address political theories and their assumptions about human nature. One question we sometimes address is whether population thinking has implications for the notion that "all men are created equal" we find in the writings of John Locke and incorporated into the Bill of Rights. The obvious reply is that political equality does not rely on the empirical assumption that people are all the same in traits and abilities. But this reply rarely satisfies those who have the worry. Students often point out that assumed biological differences between human males and females have served as justification for sexist policies of the past and might for the future if we allow it. When pressed, students are typically reluctant to admit that this is a worry just about the consequences of accepting the evolutionary picture but insist that there must also be something wrong factually with the assumption that humans vary in these ways.

The existence of human races similarly generates controversy. The standard and apparently required view in many of the courses on our campus is that human race is a fiction with no biological basis. This is a claim endorsed by many who have little or no knowledge of biological systematics. Strikingly, there is little objection to the postulation of "races" - as geographic varieties - in other species. Geographic varieties and subvarieties of fish species, for instance, are no problem at all, while geographic varieties and subvarieties of $H$. sapiens seem highly problematic and suspicious to many students. One topic that can generate lively discussion here is the use of ethnic or "racial" information in medicine. Some in the medical professions have argued that a medical doctor is not only allowed to use knowledge of a person's racial and ethnic background to better diagnose and treat disease, but professional obligation requires it where useful. Whether or not there really are human races in the sense of geographic variability, the topic generates considerable interest and passion.

Another worry appears when discussion turns to evolutionary psychology and the adaptive hypotheses of human traits that explain traits in terms of their postulated advantages for survival and reproduction. Adaptive hypotheses are not problematic as long as we restrict our discussion to approved human traits such as intelligence, sympathy, altruism, etc. Students rarely object to the hypothesis, for instance, that sympathy and what Darwin called the "social instincts" are adaptations to the human social environment. But when we turn to undesirable traits, such as tendencies to violence, territoriality, and xenophobia, attitudes in the classes change sharply. Many students are not sure what they object to here, but object they do. One initial response is to see these adaptive hypotheses as just "excusing" undesirable behavior so we don't have to try to change it. Another response sees these adaptive hypotheses as justification of the status quo to the advantage of those who benefit. Here again, while students will typically admit that it is the consequences of accepting the adaptive hypotheses in question that bother them, they are also loath to say it is just the consequences. There must be something wrong with the factual basis of the adaptive hypotheses.

In each of these worries about evolution, relative to population thinking, human races, and adaption hypotheses, there seems to be little or no appeal to Biblical literalism. And while the worries seem to begin with the assumed consequences of accepting evolution, rarely is it agreed that it is just the consequences. Students assume that there must be something wrong with the factual basis as well. This is puzzling. Most of these students accept the fundamental premises of evolution that seem to be problematic - the importance of population thinking, the existence of geographic varieties, and the adaptive value of many traitsbut they just don't accept their application to humans. There is, I believe, a way to make sense out of all of this, and I will try to do so in the next section.

\section{Exemptionalism and Antievolutionism}

In the first two books of Genesis, we get two different and not obviously consistent stories of the human creation. The most obvious response would be to see it as a problem for Biblical literalism, but what is more important, for purposes here, is the underlying conception of human nature. In Genesis, humans are special and different from other creatures, being made in "God's image." What precisely this means, we are not told, but one standard way to think about human nature theologically is in terms of a human 
"soul." Humans are what they are because they have a Godcreated soul that somehow reflects God's nature. If so, then whatever else this might involve, all those with such a divine soul are in some sense identical by virtue of having such a soul. René Descartes (1993) developed this idea within the framework of his metaphysical dualism, most strikingly in his Meditations.

According to Descartes there are two kinds of substances, a material, extended substance and an immaterial, thinking substance. For humans, these substances are joined together-a physical, extended body joined with an unextended thinking substance or soul. As students in introductory philosophy courses learn, this leads to a problem in mind-body causal interaction. First, it is not obvious how an extended material substance can cause effects in a nonmaterial, non-extended thinking substance and how the body can in turn be affected by the thinking substance. Second, because the laws of nature only apply to the extended, material substance, the non-extended, immaterial part of human nature - the soul - is not subject to the laws of nature. In contrast, nonhuman creatures are only of material body, and not thinking substance, and therefore fully subject to these laws. On the Cartesian account then, humans fit into the causal nexus of the world in a very different way than other species fit. The downside is the difficulty in seeing how humans can causally interact with the world, but the upside is that because we have a nonmaterial soul, we can act in ways that are outside the normal patterns of cause and effect. We, unlike other creatures, can transcend the laws of nature!

This dualism allowed Descartes to develop his physics without worries about its implications for human morality, in that it allowed for both a material, physical determinism with a "metaphysical freedom of the will." Material causes can necessarily produce their effects in nature, without thereby necessitating human action. For those who think it must be possible for us to act in ways other than how we in fact act to be acting freely and be morally responsible, this is a convenient metaphysical stance. Because humans are somehow outside the causal nexus of the world, they can be morally responsible in the fullest sense in that they could have acted differently. This "causal exemptionalism" is and has been attractive to philosophers for a long time and continues to be regarded as a respectable position in metaphysics and ethics. But it also reflects a deep tendency for humans to see themselves as somehow unique and exempt from the laws of nature.

There are other ways to be an exemptionalist about humans. One approach with a very long history, at least going back to Plato and his tripartite conception of the soul, is to see humans as different from other creatures on the basis of their reason - the capacity for humans to selfconsciously think about themselves and the world, repre- sent it, and have beliefs, preferences, desires, and fears about it. The philosopher Christine Korsgaard (2006, p. 116) seems to argue for such a "rationalistic exemptionalism" (that she identifies with Kant) in response to the arguments of primatologist Frans de Waal's that we can understand human moral behavior by analogy with that of other primates.

... Kant speculated that the form of self-consciousness that underlies our autonomy may also play a role in the explanation of some of the other distinctively human attributes - including culture, romantic love, and the capacity to active from self-interest. Other philosophers have noticed the connection of selfconsciousness of this sort of capacity for language. I can't go into those arguments here, but if they are correct they would provide evidence that only humans have this form of self-consciousness... If that is right, then the capacity for normative self-government and the deeper level of intentional control that goes with it is probably unique to humans beings.

And:

A form of life governed by principles and values is a very different thing from a form of life governed by instinct, desire and emotion - even a very intelligent and sociable form of life governed by instinct, desire and emotions... We have ideas about what we ought to do and to be like and we are constantly trying to live up to them. Apes do not live in that way... Even if apes are sometimes courteous, responsible and brave, it is not because they think they should be... (Korsgaard 2006, p. 117)

According to this sort of rationalistic exemptionalism, human behavior has a different and unique set of causescauses based on self-conscious commitment to "principles and values" as opposed to "mere" instinct and emotion.

Another form of exemptionalism can be found in the approach that emphasizes the importance of culture for humans. According to this "cultural exemptionalism" (usually associated with the views of the anthropologist Ruth Benedict (2006)), humans have escaped their biology by virtue of their lives being so much a product of the cultures they create - and that "creates" them. On this view, humans - unlike other creatures - create a culture in which they grow and live, a culture that determines their beliefs, attitudes, values, and goals. This is an approach sometimes associated with the "Standard Social Science Model" (see Pinker (2002) for an analysis and critique of this sort of exemptionalism).

Whichever version of exemptionalism one might accept, there are implications for how human nature and behavior are to be explained. If humans are not governed by 
precisely the same laws of nature that govern other creatures, human nature and behavior cannot be explained on precisely the same grounds as we might explain the nature and behavior of other creatures. The proper explanation of human activity and nature will therefore be unique. For Descartes, it is not clear how one can explain human behavior at all if there is no causal connection between matter and mental substance-unless one is willing to appeal to actions of a God to bridge this metaphysical divide. For other versions of exemptionalism, we can appeal to a standard sort of explanation recognized and distinguished from causal explanation, typically described as "intentional explanation." Because humans have the power to reason self-consciously and act on principles, they are different from other species and must be explained on different principles. We should therefore explain human behavior in terms of things like principles, values and ideas, or culture, rather than on the biology, emotion, and instincts humans share with other creatures.

\section{The Evolutionary Challenge}

In these types of exemptionalism, humans are unique and somehow transcend the laws of nature, by virtue of having respectively, a soul, reason, or culture. Evolution does not directly refute these exemptionalisms, but it does provide a powerful non-exemptionalist alternative that has the full force and authority of science behind it. When Darwin addressed human nature in his Descent of Man, he made it clear that humans were different from other creatures only in terms of degree - not different in "kind." Humans may have reason, but so do other species, albeit to a lesser extent. Humans may have culture and language, but so do other species to a lesser extent. For Darwin, the existence of human reason, culture, and language was explainable in each case by the same principles-primarily natural selection and sexual selection but also the effects of use and disuse and the environment. Not even Darwin's supporters could all agree with him here, though. A. R. Wallace, the codiscoverer of natural selection, believed that all creatures could be explained on evolutionary principlesexcept man, who ultimately could only be explained on the basis of intervention by a divine designer. Other supporters of Darwin, Charles Lyell and Asa Gray, similarly could not resist the temptation of this sort of divine exemptionalism, which placed the explanation of human nature ultimately outside the realm of natural law. (Richards 1987, pp. 178-185)

The strategy of Wallace, Lyell, and Gray to preserve exemptionalism by appeal to a God can be employed today but not within an evolutionary framework. Evolution seems to "naturalize" all human phenomena. It does this first by assuming that all species, $H$. sapiens included, evolved by modification from common ancestry. Because humans evolved from a common ancestor shared with bonobos and chimps, we share certain features. And second, because we evolved on the basis of the same principles, our differences are explained in terms of these same principles - even if these principles also produced differences in ability to selfconsciously reason, and create culture. There are no "nomic" exceptions in evolutionary theory for humans-we are constrained by the same natural laws that operate on other species. This does not, of course, rule out a causal role for culture and self-consciousness, but those factors must fit consistently within the evolutionary framework. We do not escape biology through reason and culture and we do not become free by escaping biology.

The effort to preserve human exemptionalism can potentially play out in many ways, including a commitment to Biblical literalism, but two prominent ways seem to have endured in the continuing objections to evolution based on the alleged sins of "reductionism" and "genetic determinism." On the standard construal of the reductionism objection, evolution commits us to the view that humans are nothing more than their constituent molecules and associated molecular and biochemical processes. Human behavior is therefore to be explained in terms of these "lower level" elements and processes. On the second and related objection, these molecules, in the form of genes, determine human behavior. If you have the gene for some behavior, you exhibit it. These objections are remarkably resilient and are made by both those who are ignorant of evolutionary theory - and by those who know much, including the biologist Richard Lewontin and paleontologist Stephen Jay Gould. Lewinton's book Not in our Genes, written with Steven Rose and Leon Kamin, is devoted in its entirety to the refutation of determinism and reductionism, as are many of the essays and books by Gould. One prominent target of Lewontin and Gould is their colleague, Edward O. Wilson. This is ironic because Wilson does not work in any of the "reductionist" subdisciplines - genetics or molecular biology_ but works instead on whole organisms in their environment and has long emphasized the role of the environment in development.

I can hardly review here the debates over reductionism and genetic determinism and the philosophical issues involved. What is of interest, however, is the function these arguments have sometimes served to preserve exemptionalism. While I do not wish to deny that there have been some biologists guilty of a single-minded reductionism or genetic determinism, they are not the rule but the exception. Geneticists in general are acutely aware of the interaction of genes with other genes and the cellular environment, as well as of the importance of the external environment. No one informed about development thinks 
that all traits are determined just by the presence of a gene. And no one who knows anything about whole organisms thinks that anything is to be gained by focusing exclusively on the molecular level. What may really be at issue is the worry that biochemical and genetic "laws" are deterministic and prevent humans from acting freely to change their lives and societies for the better. There seems to be lurking here a view much like the view described above, that humans must somehow not be constrained by the laws of biology, or they cannot have the free will required to be morally responsible and the ability to better themselves and the world. Lewontin and his coauthors seem to endorse such a view in the final words of Not in Our Genes-even though they credit biology with the unique human freedom.

For biological determinists we are unfree because our lives are strongly constrained by a relatively small number of internal causes, the genes for specific behaviors or for predisposition to these behaviors. But this misses the essence of the differences between human biology and that of other organisms. Our brains, hands, and tongues have made us independent of many single major features of the external world. Our biology has made us into creatures who are constantly re-creating our own psychic and material environments, and whose individual lives are the outcomes of an extraordinary multiplicity of intersecting causal pathways. Thus, it is our biology that makes us free. (Lewontin et al. 1984, pp. 289-290; emphasis added)

There are other ways evolution seems to challenge the various versions of exemptionalism, including its understanding of the human brain as based on an ancestral "animal" foundation, the functioning and development of individual nervous systems, and the role of chemical signaling in human behavior. I can hardly address these topics here except to note that they continue the process of explaining human nature on the principles we use to explain other creatures. In each case, they produce the worry that humans are not really different in kind from other creatures and do not have the capacity to act freely in the fullest, metaphysical sense. The bottom line is that evolution seems to challenge a very old tradition that sees human nature as different in fundamental ways from animal natures. And it implies, contrary to this tradition, that we really are subject to the same laws that govern the rest of organic nature. We may be smarter, we may have more complex cultures and means of communicating, but we are not exempt from the processes and principles that operate in nature. Even worse, just as there is variability in form, behavior, and fitness in other species, there is variability in form, behavior, and fitness of the human species. We are not all the same.

Ironically, our resistance to evolution may be partly explainable by evolution itself. The members of every species, including humans, are cued in on other members of their species and for obvious reasons. Mate recognition systems tell us who can and cannot serve as an appropriate and possible mate. Individuals who fail at this task lose at the reproduction game. Moreover, because we are intensely social creatures and depend in many ways on social structures and interaction, we must strongly distinguish members of our species from other species. The ability and tendency to both identify and prefer conspecifics are presupposed by the general qualities of animal sociality identified by E.O. Wilson-group size, cohesiveness, patterns of connectedness, differentiation of roles and integration of behavior. (Wilson 2000, pp. 16-18) A group of humans cannot have cohesiveness, for instance, unless there is some preference for other humans. Furthermore, we now know that certain structures in human brains are associated with facial recognition and cue in only on human faces. This is hardly surprising; the "speciesist" tendencies lurking behind the various versions of exemptionalism are surely useful for such social creatures as ourselves.

\section{Conclusion}

What I am arguing here is this: Evolution is more than just any old scientific theory. It challenges any view that makes humans different in kind from other animals and exempt from the laws of nature. And it challenges any view that presupposes human uniqueness, from a theological, creationist approach to those based on human reason and culture. If we focus just on the theological, creationist objection, we miss the full thrust of the evolutionary challenge. We also misunderstand the demand, from a variety of sources, for additional justification. If evolution challenges our natural tendencies to see ourselves as exempt from the laws of nature and metaphysically free, then surely we will demand greater "proof." Human exemptionalism, in all its versions, is something we do not want to give up and is perhaps what motivated my students to object to population thinking in humans, the existence of human races, and the adaptive hypotheses of negative traits.

How should we respond to these challenges? First, we need to recognize them in their full complexity. This requires that we not focus solely on creationism and Biblical literalism. These are indeed worth taking seriously but may largely be rhetorical manifestations of a deeper exemptionalism. Second, a full understanding of the philosophical challenges requires both a philosophical sensitivity to the various exemptionalist views and the will to address them in the classroom. This does not thereby imply that one needs to be a philosopher. Nonetheless, philosophical sensitivity might help avoid several problem- 
atic responses. First is the insistence that evolution implies atheism. While it is true that evolution undermines the argument for design by providing an alternative nontheistic explanation, it does not and cannot say anything about that which transcends the natural world. A scientific stance must remain agnostic about that which cannot be subject to empirical investigation. My own view is that little is gained in understanding the world by appeal to a God, and so we should simply set the question aside. This is arguably the view Darwin held, even near the end of his life. He writes in his Autobiography: "The mystery of the beginning of all things is insoluble by us; and I for one must be content to remain an agnostic." (Darwin 1958, p. 94)

The second problematic response is the insistence that evolution is a 'fact' and that is all there is to it. The obvious problem with this is the analogy with other scientific hypotheses that were once regarded as facts, but turned out to be false in some way. At the end of the nineteenth century, one standard view was that in Newtonian physics we had uncovered the most fundamental secrets of nature, and the task of science was just in mopping up the details. This was, of course, before the relativistic and quantum revolutions that seemed to falsify the prevailing theories of time, gravity, matter, and more. To just claim evolution is a 'fact' and cannot be questioned is to ignore the history of science and all its complexities. In my experience, it is also counterproductive, diminishing the authority of the support for evolution. If we say something so clearly problematic, what authority do we lose with our students?

What we can do instead is to acknowledge that no scientific theory is immune to revision, including evolution. We can highlight the empirical nature of evolution and how that makes it revisable in light of future discoveries. Evolutionary theory has been successful precisely because it is revisable in light of new observations and theorizing. Furthermore, it is the only theory of biological origins that has had this kind of success. In my own view, it will eventually give us the theoretical resources to revise and perhaps even replace the traditional intentional explanations that philosophers, cultural anthropologists, and others have focused on and that have grounded various exemptionalist approaches. (This is not to say that we will replace intentional explanations in our everyday lives, however.) Perhaps the strongest argument for evolution is something that many students might already accept: the power of science in general to predict, understand, and change the world around us can be found in our theories of evolution. To set aside our best understanding of our origins on the grounds of our own worries about the uniqueness of humanity is to act contrarily to our own best understanding of the world. By opposing evolution, we are rejecting the best tools we have to understand ourselves and our place in the world.

This answer will obviously not satisfy everyone. Those who use antievolutionary arguments to generate political power or raise money, for instance, may not be so concerned with the considerations offered here. And those who have been so indoctrinated in an antievolutionary stance that they cannot consider the arguments at all are beyond our influence as well. Nonetheless, humans are the kinds of creatures that at least sometimes respond to arguments and ideas - even if we can never free ourselves from the biological foundations for reason and selfconscious deliberation. This fact points toward one of the more interesting implications of an evolutionary approach to human nature: that we can formulate and test theories of evolution is itself a product of evolution. How can we then incorporate this ability, and its basis in reason and selfconscious deliberation, into a comprehensive and evolutionary understanding of ourselves and our place in nature? And how can we better understand its product - evolutionary theory - on such a basis? I have no answer here to these questions, but a thoroughgoing and consistent evolutionary approach demands that we eventually ask them. Scientific theories are themselves part of nature and subject to the principles that govern nature.

\section{References}

Benedict R. Patterns of culture. Boston: Houghton Mifflin; 2006.

Darwin C. The autobiography of Charles Darwin. New York: W.W. Norton; 1958.

Darwin C. On origin of species: a facsimile of the first edition. Cambridge: Harvard University Press; 1964.

Darwin C. The descent of man and selection in relation to sex. Princeton: Princeton University Press; 1981.

Descartes R. Meditations on first philosophy. Indianapolis: Hackett; 1993.

Gould SJ. The hedgehog, the fox and the magister's pox: mending the gap between science and the humanities. New York: Harmony Books; 2003.

Korsgaard CM. Morality and the distinctness of human action. In: de Waal F, editor. Primates and Philosophers: How Morality Evolved. Princeton: Princeton University Press; 2006.

Lewontin R, Rose S, Kamin LJ. Not in our genes: biology, ideology and human nature. New York: Pantheon Books; 1984.

Pinker S. The blank slate: the modern denial of human nature. London: Penguin; 2002.

Richards RJ. Darwin and the emergence of evolutionary theories of mind and behavior. Chicago: University of Chicago Press; 1987.

Segerstråle U. Defenders of the truth: the sociobiology debate. Oxford: Oxford University Press; 2001.

Smith WH. William Jennings Bryan and the social Gospel. J Am Hist 1966;53(1):41-60.

Wilson EO. Sociobiology: the new synthesis. Cambridge: Harvard University Press; 2000. 